\title{
Association Between Dental Implants and Cognitive Function in Community-dwelling Older Adults in Korea
}

\author{
Seungkook Ki', Jihye Yun' ${ }^{1}$ Jinhee Kim ${ }^{1}$, Yunhwan Lee ${ }^{1,2}$ \\ ${ }^{1}$ Department of Preventive Medicine and Public Health, Ajou University School of Medicine, Suwon, Korea; ${ }^{2}$ Institute on Aging, Ajou University \\ Medical Center, Suwon, Korea
}

Objectives: This study aimed to evaluate the association between dental implants and cognitive function in community-dwelling older adults.

Methods: Data were collected from the baseline survey (2016-2017) of the Korean Frailty and Aging Cohort Study. The study sample comprised 1115 community-dwelling people aged 70 years to 84 years who had 0-19 natural teeth. Dental implants and natural teeth were identified by panoramic radiography, while the cognitive function was assessed by the Korean version of the Mini-Mental State Examination (MMSE-KC). The association between dental implants and cognitive function was analyzed by multiple linear regression. Sensitivity analysis was performed to test for potential bias.

Results: The mean number of natural teeth in the study population was 9.50 (standard deviation [SD], 6.42), and the mean MMSE-KC score was 24.93 (SD, 3.55). In the simple univariate analysis, tooth replacement, age, sex, smoking status, alcohol consumption, body mass index, osteoporosis, number of natural teeth, periodontitis, chewing discomfort, tooth-brushing frequency, education level, monthly household income, participation in economic activity, living alone, and marital status had a significant impact on the association. After adjusting for confounders, the association between dental implants and cognitive function remained significant ( $\mathrm{B}, 0.85$; standard error, $0.40 ; p<0.05)$. Age, body mass index, periodontitis, tooth-brushing frequency, and education level were also significantly associated with cognitive function. The results of the sensitivity analyses were consistent with those of the primary analysis. Conclusions: Dental implants were associated with cognitive function in older adults living in the community. Dental implants as tooth replacements may play a role in preserving cognitive function.

Key words: Dental implant, Cognition, Cognitive reserve, Prostheses and implants, Cognitive dysfunction, Aged

Received: June 24, 2019 Accepted: September 10, 2019

Corresponding author: Yunhwan Lee, MD, DrPH Department of Preventive Medicine and Public Health, Ajou University School of Medicine, 164 World cup-ro, Youngtong-gu, Suwon 16499, Korea

\section{E-mail: yhlee@ajou.ac.kr}

This is an Open Access article distributed under the terms of the Creative Commons Attribution Non-Commercial License (http://creativecommons.org/licenses/bync/4.0/) which permits unrestricted non-commercial use, distribution, and reproduction in any medium, provided the original work is properly cited.

\section{INTRODUCTION}

Cognitive decline is highly prevalent in old age. Studies have suggested 2 significant approaches to coping with cognitive decline. One is through improvements in modifiable factors such as drinking, smoking, diet, and exercise, and the other is through the appropriate management of chronic conditions such as hypertension and diabetes mellitus [1]. However, the effectiveness of these options is questionable. In geriatrics, how to change modifiable factors is among the critical areas of focus [2]. Managing chronic conditions is also not easy in 
older adults, as doing so depends on medication intake, which in turn is challenging to ensure due to visual impairment, reduced fine motor function, and poor health literacy [3].

Implants or implantable devices provide new perspectives in this regard. They are medical devices made of 1 or more biomaterials that are intentionally placed in the body, completely or partially buried beneath the surface of the epithelium [4]. Implants can complement or replace body organs damaged due to aging [5]. Implants have less impact on an individual's lifestyle and require less direct action or complex skills. Therefore, implants can be an effective intervention with more modifiability than lifestyle modifications.

Several studies have reported a significant association between tooth loss and cognitive function [6-8]. A recent metaanalysis reported that older adults with $<20$ teeth had a $20 \%$ higher risk of cognitive decline [9]. Nevertheless, studies have rarely investigated the association between dental implants and cognitive function.

A previous study reported that dental implants could increase cerebral blood volume [10] and brain function in those with impaired brain regions [11], and reduce the imbalance and asymmetry of brain function [12]. To the best of our knowledge, no epidemiological study to date has assessed the association between dental implants and cognitive function.

We aimed to examine the association between dental implants and cognitive function in community-dwelling older adults. After determining the appropriate categories of natural teeth through a literature review, we examined the association between implants and cognitive function and tested the robustness of the results through sensitivity analyses.

\section{METHODS}

\section{Data Source}

In this cross-sectional study, we analyzed baseline data from the Korean Frailty and Aging Cohort Study (KFACS). The KFACS is a nationwide multicenter study that aimed to detect and analyze the causes and effects of frailty. The baseline survey, including 3014 community-dwelling people aged 70-84 years, was conducted in 2016-2017 with follow-up surveys planned every 2 years. Details of the design of the KFACS have been presented elsewhere [13].

We identified participants with panoramic radiography $(n=2609)$ in whom the dental anatomy could be investigated at baseline $(n=3014)$, after the exclusion of those with no panoramic radiography $(n=315)$ and illegible panoramic radiography $(n=90)$. The number of natural teeth was investigated based on panoramic radiography and calculated, excluding retained tooth roots, pontics, and implants. Wisdom teeth were included as natural teeth.

We conducted a literature review to determine the appropriate threshold for categorizing participants as having natural teeth. The presence of $\geq 20$ natural teeth reportedly ensures optimal oral function through adequate chewing capacity and efficiency [14], and in many studies, was used as a threshold to categorize people as having natural teeth $[15,16]$. A recent meta-analysis reported that the risk of cognitive decline was $20 \%$ higher in individuals with $<20$ teeth than those with $\geq 20$ teeth. [9] Thus, we set the upper limit of natural teeth as 19.

Accordingly, subjects with 0-19 natural teeth $(n=1285)$ were identified from the cohort, and finally, eligible participants $(n=1115)$ were selected after the exclusion of those with missing values $(n=170)$. The following flow chart shows the participation selection process (Figure 1).

\section{Measurements}

\section{Tooth replacement}

Tooth replacement was investigated using panoramic radiography. Dentists performed the readings. We focused on the function of the teeth and considered dental prostheses as a fixed substitute for tooth loss [6]. A pontic is an artificial tooth

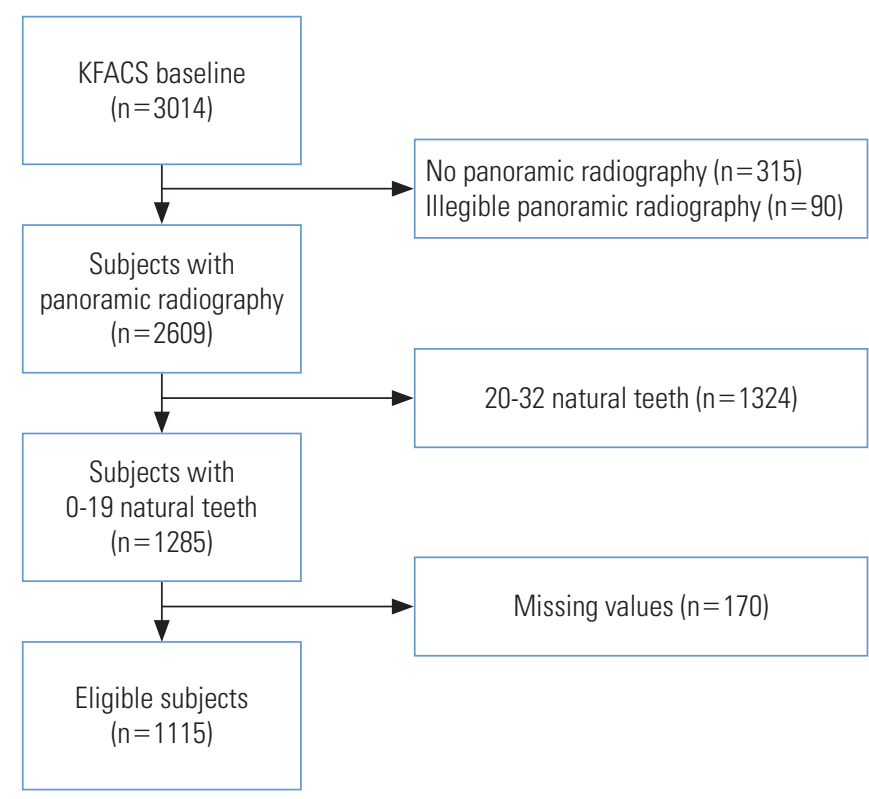

Figure 1. Flow chart of participant selection. KFACS, Korean Frailty and Aging Cohort Study. 
on a fixed partial denture that replaces a missing natural tooth, restoring its function [18]. Whereas a dental implant has its own artificial tooth root anchored into the bone, a pontic has no tooth root and is connected to the abutment teeth on either side [18]. Therefore, pontics were included as tooth replacements. As a result, tooth replacement status was classified into 4 categories: none, pontics only, pontics and implants, and implants only.

\section{Cognitive function}

The Mini-Mental State Examination (MMSE) evaluates orientation, registration, attention and calculation, recall, and language [19]. In this study, cognitive function was measured using the MMSE in the Korean version of the Consortium to Establish a Registry for Alzheimer's Disease assessment packet (MMSE-KC) [20]. The MMSE-KC differs from the original MMSE in 3 items: orientation, attention and calculation, and language. Considering the high illiteracy rate among elderly Korean people, 'reading and writing' was replaced with 'judgment' and the '100-7 calculation' was replaced with 'speaking backward' [21]. This is a validated screening test with an area under the curve of $>0.9$ for Alzheimer disease [22]. Well-trained clinical research coordinators measured the MMSE-KC scores.

\section{Covariates}

Covariates were selected based on the possible mechanism of the effect of dental implants on cognitive function. However, due to the lack of epidemiological studies, we reviewed studies on tooth loss and cognitive function [7-9]. The proposed mechanisms of the effect of tooth loss on cognitive function can be classified into 4 categories: inflammation [23$25]$, abnormal mastication [7,10-12,26,27], reverse or bidirectional causality $[28,29]$, and residual confounding in the socioeconomic domain [30]. As dental implants restore tooth function, it is expected that the abnormal mastication mechanism would be blocked. Therefore, the covariates related to the other 3 mechanisms were collected.

Demographic variables included age and sex. Health behaviors included smoking status (non-smoker, former smoker, or current smoker), alcohol consumption (none, $\leq 1 / \mathrm{wk}$, or $>1$ / $w k)$, and body mass index $\left(<23.0 \mathrm{~kg} / \mathrm{m}^{2}, 23.0-24.9 \mathrm{~kg} / \mathrm{m}^{2}\right.$, or $\geq 25.0 \mathrm{~kg} / \mathrm{m}^{2}$ ). Comorbidities included hypertension, cerebrovascular disease, coronary artery disease, asthma or chronic obstructive pulmonary disease, osteoporosis, diabetes mellitus, depression, and other psychiatric disorders. Among laboratory markers, high-sensitivity C-reactive protein (hs-CRP) $(<1.0 \mathrm{mg} / \mathrm{L}$, 1.0-3.0 mg/L, or $>3.0 \mathrm{mg} / \mathrm{L}$ ) was selected. Oral health-related variables included the number of natural teeth, periodontitis (normal, mild, moderate, severe, or edentulous), chewing discomfort (not at all, mild, moderate, or severe), and tooth-brushing frequency (0-1 time/d, 2 times/d, or $\geq 3$ times/d). Socioeconomic position (SEP) variables included education level (no formal education, primary school, middle school, or high school or higher), monthly household income $(<1000000$ Korean won [KRW], 1000 000-3 000000 KRW, or $\geq 3000000$ KRW), participation in economic activity, living alone, and marital status (married or widowed/separated/divorced/never married).

\section{Statistical Analysis}

In the descriptive analysis, quantitative data were expressed as mean \pm standard deviation, and qualitative data were expressed as frequency (\%). Comparisons of the response variable and covariates among the tooth replacement groups were performed using analysis of variance and the chi-square test. Simple univariate analyses were performed with simple linear regression for quantitative data, and the Student $t$-test and analysis of variance for qualitative data. The association between dental implants and cognitive function was analyzed by multiple linear regression. Tooth replacement was set as the explanatory variable, the MMSE-KC score as the response variable, and the covariates described above were adjusted for. A value of $p$-value $<0.05$ was considered to indicate statistical significance. Statistical analysis was performed using SAS version 9.4 (SAS Institute Inc., Cary, NC, USA).

\section{Sensitivity analysis}

Multiple sensitivity analyses were conducted. A sensitivity analysis for natural tooth categorization was conducted to adjust for selection bias. Multiple linear regression analysis was performed by changing the upper limit $(n=19)$ of the category in the range of \pm 5 . A sensitivity analysis of tooth replacement was also conducted. The pontic and implant group contained various types of tooth replacements (pontics and implants) in varying combinations. Therefore, multiple linear regression analysis was performed with the exclusion of this group.

\section{Ethics Statement}

The study protocol was approved by the Institutional Review Board of Ajou University Hospital (AJIRB-MED-MDB-19-158). All participants provided written informed consent. This article 
Table 1. Characteristics of the study population $(n=1115)$

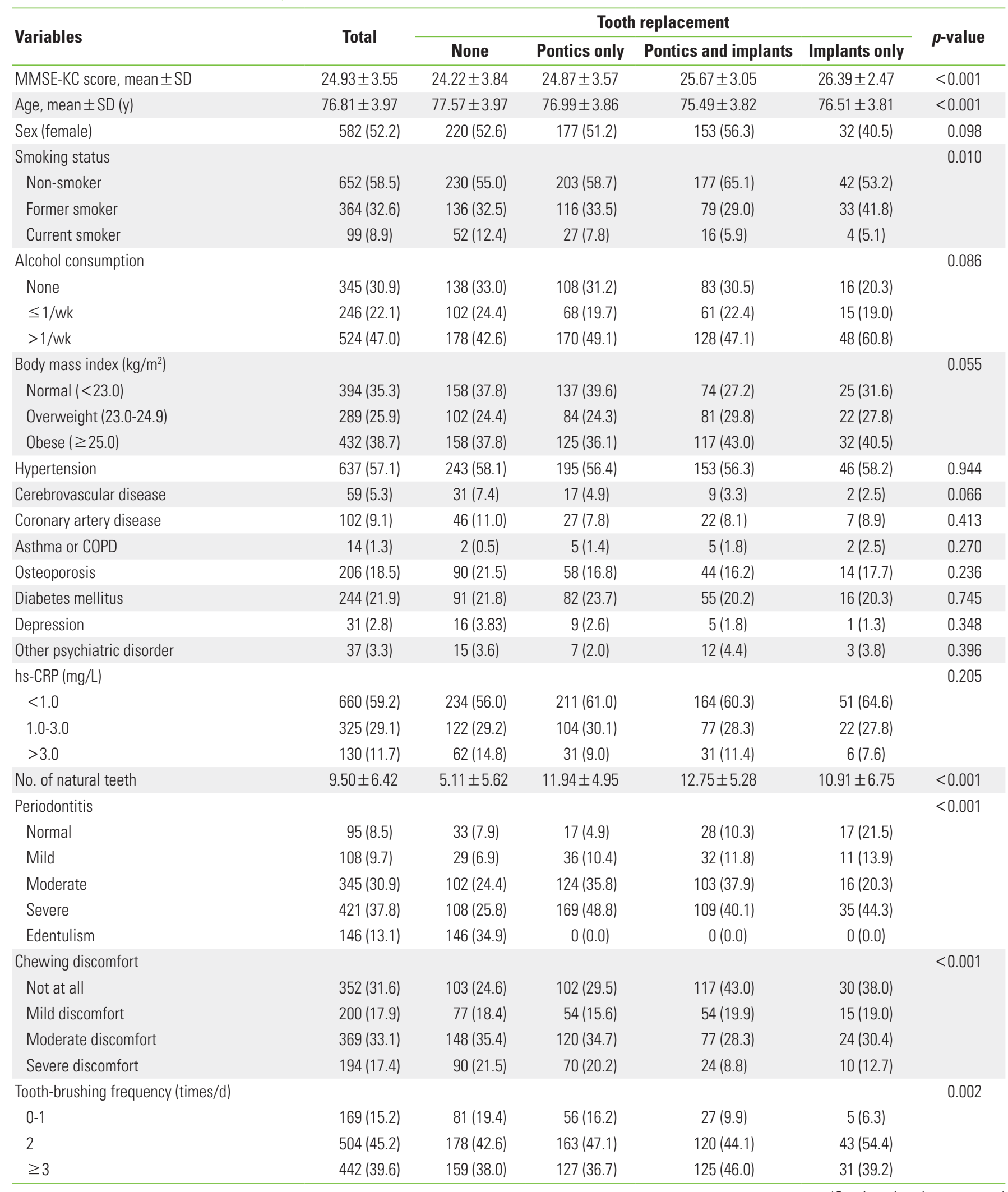


Table 1. Continued from the previous page

\begin{tabular}{|c|c|c|c|c|c|c|}
\hline \multirow{2}{*}{ Variables } & \multirow{2}{*}{ Total } & \multicolumn{4}{|c|}{ Tooth replacement } & \multirow{2}{*}{$p$-value } \\
\hline & & None & Pontics only & Pontics and implants & Implants only & \\
\hline Education level & & & & & & $<0.001$ \\
\hline Uneducated & $317(28.4)$ & $156(37.3)$ & $106(30.6)$ & $41(15.1)$ & $14(17.7)$ & \\
\hline Primary school & $308(27.6)$ & $119(28.5)$ & $98(28.3)$ & $74(27.2)$ & $17(21.5)$ & \\
\hline Middle school & $183(16.4)$ & $59(14.1)$ & $61(17.6)$ & $50(18.4)$ & $13(16.5)$ & \\
\hline High school or higher & $307(27.5)$ & $84(20.1)$ & $81(23.4)$ & $107(39.3)$ & $35(44.3)$ & \\
\hline Monthly household income (104 Korean won) & & & & & & $<0.001$ \\
\hline$\geq 300$ & $123(11.0)$ & $23(5.5)$ & $30(8.7)$ & 54 (19.9) & $16(20.3)$ & \\
\hline $100-300$ & $396(35.5)$ & $125(29.9)$ & $122(35.3)$ & $119(43.8)$ & $30(38.0)$ & \\
\hline$<100$ & $596(53.4)$ & $270(64.6)$ & $194(56.1)$ & $99(36.4)$ & $33(41.8)$ & \\
\hline Economic activity participation & $327(29.3)$ & $127(30.4)$ & $117(33.8)$ & $63(23.2)$ & $20(25.3)$ & 0.027 \\
\hline Living alone & $297(26.6)$ & $134(32.1)$ & $88(25.4)$ & $57(21.0)$ & $18(22.8)$ & 0.009 \\
\hline $\begin{array}{l}\text { Marital status (widowed/ separated/divorced/ } \\
\text { never married) }\end{array}$ & $418(37.5)$ & $172(41.1)$ & $133(38.4)$ & $89(32.7)$ & $24(30.4)$ & 0.076 \\
\hline
\end{tabular}

Values are presented as number (\%).

SD, standard deviation; MMSE-KC, Korean version of the Mini-Mental State Examination; COPD, chronic obstructive pulmonary disease; hs-CRP, high-sensitivity C-reactive protein.

is compliant with the STROBE (Strengthening the Reporting of Observational Studies in Epidemiology) guidelines [17].

\section{RESULTS}

The characteristics of the study population are shown in Table 1. Of the 1115 eligible participants, 79 had implants only, 272 had both pontics and implants, 346 had pontics only, and $418 \mathrm{had}$ none. The mean age was $76.81 \pm 3.97$ years, and the number of men was 533 (47.8\%). The mean MMSE-KC score of all participants was $24.93 \pm 3.55$. The mean MMSE-KC score was $24.87 \pm 3.57$ in the pontic group, $26.39 \pm 2.47$ in the implant group, and $25.67 \pm 3.05$ in the pontic and implant group, and $24.22 \pm 3.84$ in the no tooth replacement group.

The MMSE-KC score, age, smoking status, number of natural teeth, periodontitis, chewing discomfort, tooth-brushing frequency, education level, monthly household income, participation in economic activity, and frequency of living alone were significantly different among the tooth replacement groups.

Table 2 shows the number of natural teeth, pontics, and implants in each tooth replacement group. The pontic group had $11.94 \pm 4.95$ natural teeth and $2.92 \pm 2.05$ pontics, while the implant group had $10.91 \pm 6.75$ natural teeth and $4.57 \pm 3.17$ implants. The pontic and implant group had $12.75 \pm 5.28$ natural teeth, $4.06 \pm 2.63$ pontics, and $6.03 \pm 3.62$ implants.

In the simple univariate analysis (Table 3 ), tooth replace-
Table 2. Number of natural teeth, pontics, and implants by tooth replacement type

\begin{tabular}{lrrcc}
\hline Group & n (\%) & $\begin{array}{c}\text { No. of natural } \\
\text { teeth }\end{array}$ & $\begin{array}{c}\text { No. of } \\
\text { pontics }\end{array}$ & $\begin{array}{c}\text { No. of } \\
\text { implants }\end{array}$ \\
\hline None & 418 & $5.11 \pm 5.62$ & - & - \\
Pontic only & 346 & $11.94 \pm 4.95$ & $2.92 \pm 2.05$ & - \\
\hline Pontic and implant & 272 & $12.75 \pm 5.28$ & $4.06 \pm 2.63$ & $6.03 \pm 3.62$ \\
Implant only & 79 & $10.91 \pm 6.75$ & - & $4.57 \pm 3.17$
\end{tabular}

Values are presented as mean \pm standard deviation.

ment, age, sex, smoking status, alcohol consumption, body mass index, osteoporosis, number of natural teeth, periodontitis, chewing discomfort, tooth-brushing frequency, education level, monthly household income, participation in economic activity, living alone, and marital status showed significant association with cognitive function $(p<0.05)$.

In multiple linear regression (Table 3 ), the association between the implant only group and cognitive function was significant ( $\mathrm{B}, 0.85$; standard error [SE], 0.40; $p=0.034)$. However, the association between the pontic only group and cognitive function was not significant $(\mathrm{B}, 0.31 ; \mathrm{SE}, 0.26 ; p=0.229)$. The association of the pontic and implant group was likewise not significant ( $\mathrm{B}, 0.20 ; \mathrm{SE}, 0.29 ; p=0.494)$.

The covariates that demonstrated a significant association were age $(\mathrm{B},-0.13 ; \mathrm{SE}, 0.02 ; p<0.001)$, obesity $(\mathrm{B}, 0.53 ; \mathrm{SE}, 0.23$; $p=0.019)$, severe periodontitis $(B,-0.81 ; S E, 0.37 ; p=0.030)$, tooth-brushing frequency ( $\mathrm{B}, 0.60 ; \mathrm{SE}, 0.28 ; p=0.031$ for 2 times $/ \mathrm{d}$; $\mathrm{B}, 0.56 ; \mathrm{SE}, 0.28 ; p=0.049$ for $\geq 3$ times/d) and education level 
Table 3. Simple univariate analysis and multiple linear regression analysis of factors associated with cognitive function ( $\mathrm{n}=1115$ )

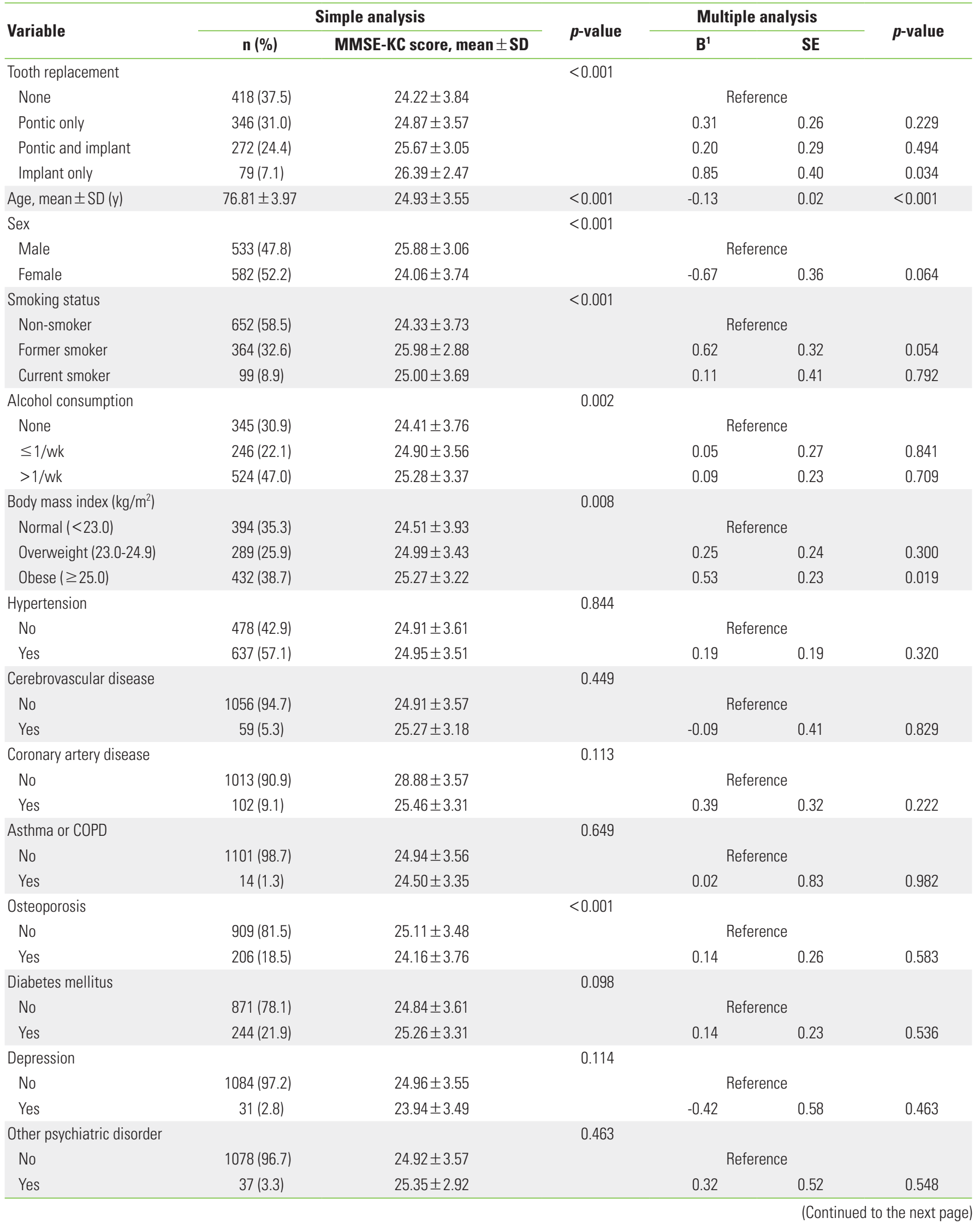


Table 3. Continued from the previous page

\begin{tabular}{|c|c|c|c|c|c|c|}
\hline \multirow{2}{*}{ Variable } & \multicolumn{2}{|c|}{ Simple analysis } & \multirow{2}{*}{$p$-value } & \multicolumn{2}{|c|}{ Multiple analysis } & \multirow{2}{*}{$p$-value } \\
\hline & n (\%) & MMSE-KC score, mean \pm SD & & $\mathbf{B}^{1}$ & SE & \\
\hline hs-CRP (mg/L) & & & 0.293 & & & \\
\hline$<1.0$ & $660(59.2)$ & $24.86 \pm 3.64$ & \multicolumn{4}{|c|}{ Reference } \\
\hline $1.0-3.0$ & $325(29.1)$ & $25.17 \pm 3.32$ & & 0.15 & 0.21 & 0.466 \\
\hline$>3.0$ & $130(11.7)$ & $24.67 \pm 3.67$ & & -0.02 & 0.30 & 0.934 \\
\hline No. of natural teeth & $9.50 \pm 6.42$ & $24.93 \pm 3.55$ & $<0.001$ & 0.01 & 0.02 & 0.522 \\
\hline Periodontitis & & & $<0.001$ & & & \\
\hline Normal & $95(8.5)$ & $25.74 \pm 2.85$ & \multicolumn{4}{|c|}{ Reference } \\
\hline Mild & $108(9.7)$ & $24.70 \pm 3.42$ & & -0.74 & 0.44 & 0.089 \\
\hline Moderate & $345(30.9)$ & $25.04 \pm 3.45$ & & -0.62 & 0.37 & 0.097 \\
\hline Severe & $421(37.8)$ & $25.11 \pm 3.48$ & & -0.81 & 0.37 & 0.030 \\
\hline Edentulous & $146(13.1)$ & $23.81 \pm 4.23$ & & -0.68 & 0.44 & 0.120 \\
\hline Chewing discomfort & & & $<0.001$ & & & \\
\hline Not at all & $352(31.6)$ & $25.09 \pm 3.58$ & \multicolumn{4}{|c|}{ Reference } \\
\hline Mild discomfort & $200(17.9)$ & $25.57 \pm 3.18$ & & 0.50 & 0.27 & 0.065 \\
\hline Moderate discomfort & $369(33.1)$ & $24.99 \pm 3.43$ & & 0.38 & 0.23 & 0.099 \\
\hline Severe discomfort & $194(17.4)$ & $23.87 \pm 3.87$ & & -0.07 & 0.28 & 0.793 \\
\hline Tooth-brushing frequency (tir & & & 0.019 & & & \\
\hline $0-1$ & $169(15.2)$ & $24.22 \pm 3.92$ & \multicolumn{4}{|c|}{ Reference } \\
\hline 2 & $504(45.2)$ & $25.03 \pm 3.45$ & & 0.60 & 0.28 & 0.031 \\
\hline$\geq 3$ & 442 (39.6) & $25.09 \pm 3.49$ & & 0.56 & 0.28 & 0.049 \\
\hline Education level & & & $<0.001$ & & & \\
\hline Uneducated & $317(28.4)$ & $22.35 \pm 3.96$ & \multicolumn{4}{|c|}{ Reference } \\
\hline Primary school & $308(27.6)$ & $25.03 \pm 3.06$ & & 2.25 & 0.26 & $<0.001$ \\
\hline Middle school & $183(16.4)$ & $26.21 \pm 2.42$ & & 3.25 & 0.31 & $<0.001$ \\
\hline High school or higher & $307(27.5)$ & $26.74 \pm 2.38$ & & 3.56 & 0.31 & $<0.001$ \\
\hline Monthly household income ( & ean won) & & $<0.001$ & & & \\
\hline$\geq 300$ & $123(11.0)$ & $26.76 \pm 2.58$ & \multicolumn{4}{|c|}{ Reference } \\
\hline $100-300$ & $396(35.5)$ & $25.60 \pm 3.31$ & & -0.07 & 0.33 & 0.827 \\
\hline$<100$ & $596(53.5)$ & $24.11 \pm 3.65$ & & -0.46 & 0.35 & 0.187 \\
\hline Economic activity participati & & & 0.003 & & & \\
\hline No & $788(70.7)$ & $25.14 \pm 3.40$ & \multicolumn{4}{|c|}{ Reference } \\
\hline Yes & 327 (29.3) & $24.41 \pm 3.85$ & & -0.32 & 0.21 & 0.134 \\
\hline Living alone & & & $<0.001$ & & & \\
\hline No & $818(73.4)$ & $25.15 \pm 3.55$ & \multicolumn{4}{|c|}{ Reference } \\
\hline Yes & $297(26.6)$ & $24.31 \pm 3.50$ & & 0.23 & 0.31 & 0.457 \\
\hline Marital status & & & $<0.001$ & & & \\
\hline Married & $697(62.5)$ & $25.32 \pm 3.58$ & \multicolumn{4}{|c|}{ Reference } \\
\hline $\begin{array}{l}\text { Widowed/separated/ } \\
\text { divorced/never married }\end{array}$ & $418(37.5)$ & $24.29 \pm 3.41$ & & 0.56 & 0.32 & 0.076 \\
\hline
\end{tabular}

SD, standard deviation; SE, standard error; MMSE-KC, Korean version of the Mini-Mental State Examination; COPD, chronic obstructive pulmonary disease; hsCRP, high-sensitivity C-reactive protein.

'Regression coefficient.

$(\mathrm{B}, 2.25 ; \mathrm{SE}, 0.26 ; p<0.001$ for primary school; $\mathrm{B}, 3.25 ; \mathrm{SE}, 0.31$, $p<0.001$ for middle school; $\mathrm{B}, 3.56 ; \mathrm{SE}, 0.31 ; p<0.001$ for high school or higher).
In the sensitivity analysis for natural tooth categorization, the implant only group showed a significant association with upper limits between 19 and 22. However, neither the pontic 
group nor the pontic and implant group showed significant relationships in any category (Supplemental Material 1).

An additional sensitivity analysis was performed by linear regression, excluding the pontic and implant group (Supplemental Material 2). The implant group also showed a significant association ( $\mathrm{B}, 0.92 ; \mathrm{SE}, 0.42 ; p=0.030$ ); the pontic group showed no significant association ( $B, 0.43 ; \mathrm{SE}, 0.27 ; p=0.120$ ).

\section{DISCUSSION}

In community-dwelling older adults with 0-19 natural teeth, cognitive function was significantly higher among those with implants than among those with neglected tooth loss $(B, 0.85$; $\mathrm{SE}, 0.40 ; p=0.034)$. However, the effects of implants should be carefully interpreted. The mean number of implants in the implant group was 4.57, making it difficult to interpret the regression coefficient merely according to the presence of an implant.

However, the pontic and implant groups did not show significant relationships with cognitive function despite the inclusion of implants. There may be 2 reasons for this finding. First, the pontic and implant group was heterogeneous. The abutments of a pontic can be either natural teeth or implants, and the number of abutments may be different even though the number of pontics is the same [18]. Therefore, it is challenging to classify older adults with both pontics and implants into a single group. Second, there is an interaction between the pontic and the implant. Due to the absence of a root, the load on the pontic is transmitted to the abutment. If the abutment is an implant, the load of the pontic is transmitted to the implant. The disequilibrium of force transmitted to the implant can be a cause of implant failure [31,32].

The mechanisms of implants on cognitive function are indissolubly linked with those of tooth loss on cognitive function. As already reviewed, the mechanisms through which tooth loss may be associated with cognitive function can be classified into 4 categories: (1) inflammation, (2) abnormal mastication, (3) reverse or bidirectional causality, and (4) residual confounding in the socioeconomic domain.

In terms of the inflammatory mechanism, increased levels of proinflammatory factors such as CRP, tumor necrosis factor a, interleukin (IL)-1, IL-6, and a-1-antichymotrypsin due to infections caused by poor oral health, including tooth loss and periodontitis, lead to chronic systemic inflammation, which plays a pivotal role in cognitive decline [23-25].
Abnormal mastication mechanisms may act through 3 pathways. First, since mastication stimulates the brain, reduced mastication leads to cognitive decline through a reduction in the strength of brain activation $[11,26]$, and asymmetric mastication induces asymmetric brain activity [12]. Second, since mastication increases cerebral blood flow, abnormal mastication reduces cerebral blood flow [10]. Third, abnormal mastication leads to poor oral intake, resulting in cognitive decline $[7,27]$.

Reverse causality or bidirectional causality may account for this association, in that when the cognitive decline occurs, the ability to perform activities of daily living (ADLs) such as oral hygiene and dental care may be impaired $[28,29]$.

Residual confounding in the socioeconomic domain could play a role since tooth loss is a surrogate marker of SEP. It is impossible to assess the independent role of tooth loss in cognitive decline due to the strong link between tooth loss and SEP [30].

Based on the above review of the mechanism of tooth loss on cognitive function, a mechanism of dental implants on cognitive function can be proposed. First, dental implants can affect cognitive function by reducing the degree of abnormal mastication. Some previous studies showed that dental implants increase cerebral blood flow [10] and improve the asymmetry of brain function [12], providing support for this mechanism.

In terms of reverse causality, dental implants have significant implications. As dental implants function independently of the ability to perform ADLs, they are also useful in older adults with cognitive decline. Cognitive function was partially reversed when mastication was restored through artificial crowns in mice without molars [33]. Cognitive decline was alleviated through occlusion rehabilitation in long-term molarfree mice [34]. In humans, dental implants have been reported to enhance brain function in those with cognitive impairment [11].

The cognitive reserve could explain the effect of implants on cognitive function through the integration of these mechanisms. The concept of cognitive reserve explains the discrepancy between the degree of brain changes and the severity of clinical outcomes resulting from individual differences in reserve and compensation [35]. A person with a higher cognitive reserve can be more resistant to brain changes and can better maintain cognitive function. Cognitive reserve is an active phenomenon that can be supplemented through life ex- 
periences such as education and occupational achievements [36], and it may prevent or reduce pathologic brain changes [37]. Individual differences in cerebral blood flow and the neural network have been presented as the underlying mechanisms of cognitive reserve [35,37]. In this context, dental implants could augment cognitive reserve through their role as adequate replacements for tooth loss.

This discussion can be extended to all implants, not just dental implants. That is, by complementing or replacing damaged body organs, implants can contribute to the preservation of cognitive reserve. Other implants, such as cochlear implants [38] and intraocular lens implants [39], have also been reported to elicit cognitive improvements in older adults through the replacement of damaged organs; however, those types of implants directly affect cognitive function, unlike dental implants.

However, there are also limitations to implants. Dental implants are more invasive than pontics. Because contraindications to dental implants include medical conditions such as acute illness and uncontrolled metabolic diseases [18], people with implants may be medically healthier than those without them. The same point holds for extending the discussion across implantable devices. It seems clear that implantable devices are less safe than other medical devices, such as wearable devices.

Our study has various strengths. First, it was designed and performed based on a mechanism associating tooth loss with cognitive function. We focused on the mechanism of abnormal mastication, which can be improved with dental implant use, and the factors related to the other mechanism were selected and adjusted for. The level of hs-CRP was adjusted as a confounder related to the inflammation mechanism. Reverse causality was adjusted using various oral health variables. We attempted to resolve the issue of residual socioeconomic confounding by adjusting for a significantly higher number of SEP items than previous studies.

Second, participants' oral condition was objectively evaluated based on panoramic radiography. Most previous studies were based on questionnaires, while those with objective evaluations had small study populations. Third, multiple sensitivity analyses were conducted to adjust for selection bias.

To the best of our knowledge, our study is the first epidemiological study to reveal the association between dental implants and cognitive function. While most previous studies only focused on the association between tooth loss and cogni- tive function, the very few that concentrated on the association between dental implants and cognitive function were experimental and enrolled few participants [10-12]. Therefore, this study is valuable, in that it showed the effect of implants on cognitive function in a real-world setting based on data from a large study population.

However, our study has some limitations. First, it had a crosssectional design, which did not allow for the sufficient inference of causality. A longitudinal study based on KFACS followup data should be conducted in the future. Next, there was no information on the position of tooth loss and tooth replacement. Further research should be based on a more detailed reading of panoramic radiography.

Implant use as a treatment to complement or replace damaged organs will increase in response to trends in aging [5] Our study shows that implants have the potential to prevent cognitive decline by restoring the function of damaged organs. Furthermore, they can be combined with information technology such as biosignal monitoring, enabling them to play a more active role in the prevention of cognitive impairment [40].

In conclusion, our study showed that dental implants were associated with cognitive function in community-dwelling older adults. Dental implants as tooth replacements may contribute to the prevention of cognitive impairment by preserving cognitive reserve.

\section{SUPPLEMENTAL MATERIALS}

Supplemental materials are available at https://doi.org/10. 3961/jpmph.19.163.

\section{CONFLICT OF INTEREST}

The authors have no conflicts of interest associated with the material presented in this paper.

\section{ACKNOWLEDGEMENTS}

This work was supported by the Korea Health Technology R\&D Project through the Korean Health Industry Development Institute (KHIDI), the Ministry of Health and Welfare, Republic of Korea (grant No. HI15C3153). 


\section{AUTHOR CONTRIBUTIONS}

Conceptualization: SK, JY, YL. Data curation: SK, JK. Formal analysis: SK. Funding acquisition: SK, YL. Methodology: SK, JY, YL. Project administration: SK, JK. Visualization: SK. Writing original draft: SK. Writing - review \& editing: SK, JY, JK, YL.

\section{ORCID}

Seungkook Ki https://orcid.org/0000-0002-4374-8495

Jihye Yun https://orcid.org/0000-0001-6692-4909

Jinhee Kim https://orcid.org/0000-0001-6570-0719

Yunhwan Lee https://orcid.org/0000-0001-8484-4750

\section{REFERENCES}

1. World Health Organization. Risk reduction of cognitive decline and dementia: WHO guidelines [cited 2019 Jun 1]. Available from: https://apps.who.int/iris/bitstream/handle/10665/ 312180/9789241550543-eng.pdf?ua=1.

2. Gierc M, Brawley L, Rejeski WJ. Self-management of health behavior. In: Halter JB, Ouslander JG, Studenski S, High KP, Asthana S, Supiano MA, editors. Hazzard's geriatric medicine and gerontology. 7th ed. New York: McGraw-Hill Education; 2017, p. 151-156.

3. Pilotto A, Martin FC. Comprehensive geriatric assessment. Cham: Springer; 2018, p. 3.

4. Williams DF. The Williams dictionary of biomaterials. Liverpool: Liverpool University Press; 1999, p. 173.

5. Manivasagam G, Dhinasekaran D, Rajamanickam A. Biomedical implants: corrosion and its prevention-a review. Recent Pat Corros Sci 2010;2:40-54.

6. Spear F. Implants or pontics: decision making for anterior tooth replacement. J Am Dent Assoc 2009;140(9):1160-1166.

7. Furuta M, Komiya-Nonaka M, Akifusa S, Shimazaki Y, Adachi M, Kinoshita T, et al. Interrelationship of oral health status, swallowing function, nutritional status, and cognitive ability with activities of daily living in Japanese elderly people receiving home care services due to physical disabilities. Community Dent Oral Epidemiol 2013;41(2):173-181.

8. Saito S, Ohi T, Murakami T, Komiyama T, Miyoshi Y, Endo K, et al. Association between tooth loss and cognitive impairment in community-dwelling older Japanese adults: a 4-year prospective cohort study from the Ohasama study. BMC Oral Health 2018;18(1):142.
9. Cerutti-Kopplin D, Feine J, Padilha DM, de Souza RF, Ahmadi M, Rompré $\mathrm{P}$, et al. Tooth loss increases the risk of diminished cognitive function: a systematic review and meta-analysis. JDR Clin Trans Res 2016;1(1):10-19.

10. Miyamoto I, Yoshida K, Tsuboi Y, lizuka T. Rehabilitation with dental prosthesis can increase cerebral regional blood volume. Clin Oral Implants Res 2005;16(6):723-727.

11. Okamoto N. Effect of occlusal support by implant prostheses on brain function. J Prosthodont Res 2011;55(4):206-213.

12. De Cicco V, Barresi M, Tramonti Fantozzi MP, Cataldo E, Parisi V, Manzoni D. Oral implant-prostheses: new teeth for a brighter brain. PLoS One 2016;11(2):e0148715.

13. Won CW, Lee Y, Choi J, Kim KW, Park Y, Park H, et al. Starting construction of frailty cohort for elderly and intervention study. Ann Geriatr Med Res 2016;20(3):114-117.

14. Gotfredsen K, Walls AW. What dentition assures oral function? Clin Oral Implants Res 2007;18 Suppl 3:34-45.

15. World Health Organization. Recent advances in oral health: report of a WHO Expert Committee; 1992 [cited 2019 Sep 20]. Available from: https://apps.who.int/iris/handle/10665/39644.

16. Komiyama T, Ohi T, Miyoshi Y, Murakami T, Tsuboi A, Tomata Y, et al. Association between tooth loss, receipt of dental care, and functional disability in an elderly Japanese population: the Tsurugaya project. J Am Geriatr Soc 2016;64(12):2495-2502.

17. von Elm E, Altman DG, Egger M, Pocock SJ, Gøtzsche PC, Vandenbroucke JP, et al. The Strengthening the Reporting of Observational Studies in Epidemiology (STROBE) statement: guidelines for reporting observational studies. Lancet 2007; 370(9596):1453-1457.

18. Rosenstiel SF, Land MF, Fujimoto J. Contemporary fixed prosthodontics. 5th ed. St. Louis: Elsevier; 2016, p. 546-547.

19. Folstein MF, Folstein SE, McHugh PR. "Mini-mental state". A practical method for grading the cognitive state of patients for the clinician. J Psychiatr Res 1975;12(3):189-198.

20. Lee JH, Lee KU, Lee DY, Kim KW, Jhoo JH, Kim JH, et al. Development of the Korean version of the Consortium to Establish a Registry for Alzheimer's Disease Assessment Packet (CERADK): clinical and neuropsychological assessment batteries. J Gerontol B Psychol Sci Soc Sci 2002;57(1):P47-P53.

21. Lee KS, Cheong HK, Oh BH, Hong CH. Comparison of the validity of screening tests for dementia and mild cognitive impairment of the elderly in a community: K-MMSE, MMSE-K, MMSE-KC, and K-HDS. J Korean Neuropsychiatr Assoc 2009; 48(2):61-69 (Korean).

22. Kim KW, Lee DY, Jhoo JH, Youn JC, Suh YJ, Jun YH, et al. Diag- 
nostic accuracy of mini-mental status examination and revised hasegawa dementia scale for Alzheimer's disease. Dement Geriatr Cogn Disord 2005;19(5-6):324-330.

23. Tan ZS, Beiser AS, Vasan RS, Roubenoff R, Dinarello CA, Harris $\mathrm{TB}$, et al. Inflammatory markers and the risk of Alzheimer disease: the Framingham Study. Neurology 2007;68(22):19021908.

24. Kamer AR, Craig RG, Dasanayake AP, Brys M, Glodzik-Sobanska L, de Leon MJ. Inflammation and Alzheimer's disease: possible role of periodontal diseases. Alzheimers Dement 2008; 4(4):242-250.

25. Watts A, Crimmins EM, Gatz M. Inflammation as a potential mediator for the association between periodontal disease and Alzheimer's disease. Neuropsychiatr Dis Treat 2008;4(5): 865-876.

26. Sakamoto K, Nakata H, Kakigi R. The effect of mastication on human cognitive processing: a study using event-related potentials. Clin Neurophysiol 2009;120(1):41-50.

27. Weijenberg RA, Delwel S, Ho BV, van der Maarel-Wierink CD, Lobbezoo F. Mind your teeth-The relationship between mastication and cognition. Gerodontology 2019;36(1):2-7.

28. Grabe HJ, Schwahn C, Völzke H, Spitzer C, Freyberger HJ, John $\mathrm{U}$, et al. Tooth loss and cognitive impairment. J Clin Periodontol 2009;36(7):550-557.

29. Syrjälä AM, Ylöstalo P, Ruoppi P, Komulainen K, Hartikainen S, Sulkava $R$, et al. Dementia and oral health among subjects aged 75 years or older. Gerodontology 2012;29(1):36-42.

30. Matthews JC, You Z, Wadley VG, Cushman M, Howard G. The association between self-reported tooth loss and cognitive function in the REasons for Geographic And Racial Differences in Stroke study: an assessment of potential pathways. J Am Dent Assoc 2011;142(4):379-390.
31. Duyck J, Van Oosterwyck H, Vander Sloten J, De Cooman M, Puers R, Naert I. Magnitude and distribution of occlusal forces on oral implants supporting fixed prostheses: an in vivo study. Clin Oral Implants Res 2000;11(5):465-475.

32. Iplikçioğlu H1, Akça K. Comparative evaluation of the effect of diameter, length and number of implants supporting threeunit fixed partial prostheses on stress distribution in the bone. J Dent 2002;30(1):41-46.

33. Watanabe K, Ozono S, Nishiyama K, Saito S, Tonosaki K, Fujita $M$, et al. The molarless condition in aged SAMP8 mice attenuates hippocampal Fos induction linked to water maze performance. Behav Brain Res 2002;128(1):19-25.

34. Mullane $S$, Loke W. Influence of short-term side effects on oral sleep appliance compliance among CPAP-intolerant patients: an objective monitoring of compliance. J Oral Rehabil 2019; 46(8):715-722.

35. Stern Y. Cognitive reserve. Neuropsychologia 2009;47(10): 2015-2028.

36. Scarmeas N, Stern Y. Cognitive reserve and lifestyle. J Clin Exp Neuropsychol 2003;25(5):625-633.

37. Stern Y. Cognitive reserve in ageing and Alzheimer's disease. Lancet Neurol 2012;11(11):1006-1012.

38. Mosnier I, Bebear JP, Marx M, Fraysse B, Truy E, Lina-Granade G, et al. Improvement of cognitive function after cochlear implantation in elderly patients. JAMA Otolaryngol Head Neck Surg 2015;141(5):442-450.

39. Ishii K, Kabata T, Oshika T. The impact of cataract surgery on cognitive impairment and depressive mental status in elderly patients. Am J Ophthalmol 2008;146(3):404-409.

40. Serruya MD, Kahana MJ. Techniques and devices to restore cognition. Behav Brain Res 2008;192(2):149-165. 